\title{
FORMAS DE LEER EL ENSAYO ARGENTINO EN EL TRÁNSITO DE UN SIGLO A OTRO (XX AL XXI)
}

Claudio Maíz ${ }^{1}$

Resumen: Este artículo se compone de dos partes. La primera busca establecer algunas formas de lectura densa de la cultura literaria y en particular del ensayo. En la segunda se traza un mapa tentativo de la ensayística argentina que va del XX al XXI basado en las líneas teóricas iniciales.

Palabras clave: lecturas densas; cultura literaria; ensayo argentino.

Abstract: This article is made up of two parts. The first seeks to establish some forms of dense reading of the literary culture and in particular of the essay. In the second, a tentative map of Argentine essays is drawn up, which goes from XX to XXI based on the initial theoretical lines.

Key words: dense readings; literary culture; Argentine essay.

\section{Enfoques densos de la cultura literaria: leer el ensayo}

Al parecer los cambios de un siglo a otro constituyen un cronotopo de sumo interés para los estudios de la cultura. Por caso, el recorrido que va del siglo XIX al XX en América Latina ha merecido numerosos enfoques desde la filosofía, la ciencia, la literatura. Los estudios literarios especialmente se ocuparon de aquel entresiglo porque en América Latina se había gestado, y luego madurado, el modernismo, con materiales culturales arrastrados del XIX y fusionados con las novedades del XX, pero curiosamente sin eludir la literatura clásica española o el interés por la cultura antigua. A casi dos décadas de haber enfrentado un nuevo entresiglo, quisiéramos comenzar estas reflexiones intentando una caracterización del intervalo temporal que va del XX al XXI.

En primer lugar, porque desde una perspectiva crítica existen diversos enfoques que permiten analizar estos fenómenos de la cultura.

${ }^{1}$ Doctor en Letras por la Universidad de Cuyo. Profesor Titular Efectivo de la Catedra Literatura Hispanoamericana II (siglo XX) en la Facultad de Filosofía y Letras da Universidad Nacional de Cuyo - UNCuyo/CONICET, Argentina. 
Algunos de ellos ponen énfasis en los contextos, otros, en las temáticas que apoyan las periodizaciones, están asimismo las que detectan cambios estructurales o las que consideran las desterritorializaciones, entre otras. En segundo lugar porque existe un factor temporal que facilita, no obstante, cierta mirada menos sesgada para el análisis crítico. Los efectos positivos del factor temporal funcionan siempre y cuando nos alejamos del fenómeno estudiado y se torna problemático en la medida en que nos ubicamos muy cerca del mismo. Es una regla de oro de las ciencias humanas, pero no una regla restrictiva. En efecto, los fenómenos más cercanos en los que nos encontramos inmersos carecerían de una mirada crítica, que solamente serían factibles si inexorablemente se cumpliera el requisito del paso del tiempo. Por lo que se hace necesario hablar de "temporalidades del presente" como ha escrito Josefina Ludmer (2002, p. 91-112) a fin de identificar lo que importa del presente, que habrán de ser (o no) los materiales que -ahora sí, con el paso del tiempo, la historiografía usará. De este modo queremos proponer una mirada analítica que en principio procura situarse desde un lugar totalizante, no focalizada en un único epifenómeno y que soslaya la perspectiva temporal transcurrida para hablar de hechos presentes o cercanos a él. En virtud de ello seguimos la idea de una lectura densa del ensayo que propone Liliana Weinberg, pero que puede ser extensible a la cultura literaria en general. Dice la autora:

Lejos entonces de contemplar las operaciones del ensayista como estrategias ligeras, y lejos de someter la lectura del ensayo a un proceso de lectura delgada, propongo contemplarlas en toda su complejidad como ligadas a una visión de mundo y a un horizonte epistémico, ético y estético con que el autor entra en diálogo a través del ensayo y que sólo puede descubrirse a través de una interpretación densa. Propongo ver también las operaciones ensayísticas como ligadas a la comunicación intersubjetiva, el papel de mediación que adopta el escritor y al establecimiento de vínculos sociales sobre la base de un diálogo intelectual (WEINBERG, 2017, p. 20).

La mirada densa del ensayo involucra aspectos que van más allá del texto al momento de entrar en interrelación con lo social, entendido como un abigarrado conjunto de elementos que van del diálogo con otros textos a la capacidad perlocutiva del texto en un campo mayor. La lectura 
Formas de leer el ensayo argentino en el tránsito de un siglo a otro (XX al XXI) | 11

densa del ensayo también tiene una vinculación con enfoques "totalizantes". Al respecto, nos detenemos en tres antecedentes en cuanto a la búsqueda la identificación de cambios de episodios culturales en contextos amplios. Seguimos los pasos de Fredric Jameson cuando al abordar el posmodernismo lo hace desde un enfoque "totalizador".

En los viejos tiempos, -escribe Jameson- la abstracción era con seguridad una de las maneras estratégicas en que los fenómenos, en particular los históricos podían enajenarse y desfamiliarizarse; cuando uno está inmerso en lo inmediato -la experiencia, año tras año, de los mensajes culturales e informacionales, los hechos sucesivos, las prioridades urgentes-, la distancia abrupta que permite un concepto abstracto, una caracterización más global de las secretas afinidades entre esos dominios aparentemente autónomos e inconexos y de los ritmos y secuencias ocultas de cosas que por lo común sólo recordamos aisladas y una por una, es un recurso único, en particular si tiene en cuenta que la historia de los años precedentes siempre es lo que nos resulta menos accesible (JAMESON, 2002, p. 58).

En segundo lugar, reafirmamos aún más esta orientación, con las advertencias de Rafael Gutiérrez Girardot sobre la necesidad de ampliar las tramas históricas y culturales. El crítico abogaba, refiriéndose al modernismo hispanoamericano, "por situar las letras hispánicas de fin de siglo en el contexto europeo" (GUTIERREZ GIRARDOT, 2004, p.19). De manera que pensar las variantes de un género literario puede centrarse nada más que en ello o bien intentar abordar los cambios probables de un género estrechamente ligado a las amplias circunstancias en el que se produce. Aunque, el ensayo no sea un género que se especializa en una dimensión temporal determinada, oscila entre, por una parte, la memoria, la historia y el olvido, por otra, a través de expectaciones futuras y finalmente, posee un anclaje muy denso al momento de referirse al presente. Esta última dimensión temporal lo sitúa como el discurso más propenso para la polémica que encara y encarna la figura del intelectual. De ahí que pensar cambios en el ensayo argentino en el entresiglo demande algunas precisiones respecto del complejo entramado que establece con su circunstancia y la figura del intelectual.

El tercer esfuerzo por visualizar alteraciones en el campo cultural dentro de contextos amplios que rebasan una estricta concepción 


\section{2 | Claudio Maíz}

cronológica podría aludirse al estudio de la novela hispanoamericana de Cedomil Goic (1972, p.105 y ss) cuando planteó que el Naturalismo consistía en una tendencia, cuyo inicio se hallaba en el siglo XIX y su final se situaba en el XX. Dicha tendencia no era otra cosa que el "positivismo en literatura". En resumen, nos interesan entonces estas miradas dilatadas, de larga duración, antes que ceñirnos a los bordes socioculturales lábiles por cierto de un texto literario. Así, el Naturalismo visto como un ciclo a horcajadas entre dos siglos puede auxiliarnos, por añadidura, como modelo para abordar un tránsito secular análogo, esto es, del siglo XX al siglo XXI. Al igual que como unos artistas e intelectuales debieron afrontar los dilemas de la Modernidad, otros -los que nos interesan- se enfrentan a un panorama más abigarrado y complejo, que incluye desde el punto de vista cultural, la posmodernidad.

\section{El ensayo entre texto y contexto}

Por un lado, gracias a que es preciso ampliar los márgenes de los escenarios culturales es factible descubrir "secretas afinidades" o "secuencias ocultas", en palabras de Jameson, que solamente una imaginación relacional puede poner en correlación. Por otro, es necesario encontrar los hilos que ponen el texto en conexión con el "afuera". El formalista ruso Boris Eichenbaum decía que

La literatura, como cualquier otro orden específico de fenómenos, no se engendra a partir de los hechos de otros órdenes, y, por lo tanto, no es reducible a los mismos. Las relaciones entre los hechos del orden literario y los hechos exteriores no pueden ser causales, sino que deben ser únicamente relaciones de correspondencia, interacción, dependencia o condicionamiento (EICHENBAUM, 1992, p. 245).

En el texto sobre la evolución literaria, por su lado, Iuri Tynianov aclaraba que era insuficiente el estudio "inmanente" de la obra en cuanto

2 Dice concretamente Goic: "El Naturalismo en la novela hispanoamericana se prolonga en su madura vigencia literaria entre 1890 y 1934 /.../Sus nuevos rasgos se acompañan con una concepción cientificista de la literatura /.../ Este aspecto particular y toda la concepción naturalista hace posible decir con relación a este periodo que el Naturalismo es el positivismo en literatura”. 
Formas de leer el ensayo argentino en el tránsito de un siglo a otro (XX al XXI) | 13 sistema, fuera de su correlación con el sistema de la literatura. Y agregaba que ni la literatura contemporánea podía ser estudiada de manera aislada. La existencia de un hecho en cuanto hecho literario depende de su calidad diferencial (es decir, de su correlación bien con el orden literario, bien un orden extraliterario), con otras palabras, de su función (TYNIANOV, 1992, p.255). ${ }^{3}$ De manera que la teoría literaria muy tempranamente postuló la importancia de los contextos de producción, con serias advertencias de no caer en vulgares sociologismos ni dependencias causalística. Pero todavía debiéramos dar mayor solidez a la perspectiva esbozada hasta aquí, haciendo nuestras las palabras de Chartier:

Por otra parte, la historia cultural coloca en lugar central la cuestión de la articulación de las obras, representaciones y prácticas con las divisiones del mundo social que, a la vez son incorporadas y producidas por los pensamientos y las conductas. /.../ toda creación inscribe en sus formas y sus temas una relación con las estructuras fundamentales que, en su momento y un lugar dados, organizan y singularizan la distribución del poder, la organización de la sociedad o la economía de la personalidad (CHARTIER, 1992, p. X y $\mathrm{XI})$.

En suma, nuestro interés se enfoca en diseñar una red que comprenda obras, representaciones y prácticas, todos inmersos en el universo social al cual pertenecen. Lo dicho se complementa, en esta breve introducción desde donde queremos caracterizar el nuevo entresiglo, con lo que Rita De Grandis formula en una cadena de interrogantes que permiten dimensionar el estado de un género del yo, en el que se ubica el ensayo, aunque en un nuevo entorno que es el del pleno dominio de la revolución tecnológica:

¿Qué relevancia tiene preguntarse por el destino de este género literario, expresión del libre discurso reflexivo de un yo moderno en búsqueda de nuevas figuraciones de la conciencia, cuando en la posmodernidad o modernidad tardía, la literatura y su yo parecieran haber perdido su novedad y radicalidad crítica, fagocitados por el fetichismo de la mercancía o el de la virtualidad tecnológica? ¿Qué

\footnotetext{
${ }^{3}$ Subrayado original.
} 
nuevas bifurcaciones modélicas y qué bases históricas ha adoptado "el centauro de los géneros", aquel que en el siglo XIX hiciera de América su laboratorio histórico? ¿Cuáles son los límites del ensayo dentro del conjunto de los saberes y géneros instituidos, cuando en su presente etapa parecieran haberse fundido en la modelización ensayística la filosofía y la ficción, resultado de la operación lingüísticosemiótica que disparara el estructuralismo y las diversas formulaciones del pos-estructuralismo? (DE GRANDIS, 2012, p. 494).

Este conjunto de interrogantes concierne al estado en el que se encuentra el ensayo luego de su paso de un siglo a otro. Por tanto es viable pensar el género en su relación con una gran tendencia ideológica que atañe a probables reubicaciones del ensayo en el campo cultural. En otras palabras, algunos de los anteriores interrogantes tienen respuestas si se considera la tendencia que observamos en este último entresiglo. Se trata de un movimiento de espectro amplio que llamamos la restauración del liberalismo, con diferentes modalidades que van desde liberalismo apoyado en el terror (la etapa de las crueles dictaduras de los años 70 y 80); bajo las democracias condicionadas (su faceta más descarnada ocurre durante parte de los 80 y la década de los 90); por fin, la implosión de esta restauración liberal en pleno pasaje hacia el siglo XXI (los acontecimientos del año 2001 en la Argentina) En este marco ampliado en que fuerzas políticas y económicas se entretejen en la diagramación de los textos culturales, queremos pensar los probables cambios de la ensayística argentina. A la manera de enorme campo agónico que se encuentra atravesado en diversas direcciones por múltiples tópicos, temáticas, oposiciones. El espectro de la negatividad es variado que va del desacuerdo (Rancière), a la crítica (Adorno), el conflicto (Marx, Engels) y el disenso (Buela). Las variantes no son de matices sino que ayudan a organizar el campo cultural en el que se activan los textos ensayísticos. Si detalláramos los episodios más significativos que componen el campo delimitado por la gran tendencia de la restauración liberal, enumeraríamos los siguientes: la dictadura militar de 1976; la guerra de Malvinas y el fin de la dictadura; las democracias condicionadas por el consenso de Washington; la implosión del sistema político en el 2001; la emergencia del kirchnerismo. 
Formas de leer el ensayo argentino en el tránsito de un siglo a otro (XX al XXI) | 15

Un mapeo para el entresiglo. ¿Renovación temática, cambio estructural?

Auxiliados por algunas nuevas direcciones en torno a la manera de como leer la literatura en la actualidad vamos a intentar bosquejar rápidamente un mapa de algunas expresiones ensayísticas que componen un conjunto mayor. Hay un dato incontrastable, la ensayística de entresiglo ha abandonado ciertos temas que habían sido de vital importancia para otras promociones de ensayistas: la identidad nacional, el "ser nacional", los destinos de la "patria grande", el problema de la integración, el imperialismo y otros tantos, que han estado muy ligados a los contextos en los que se produjeron. Asimismo dentro del campo cultural la figura del intelectual ha ido mutando como consecuencia de la cada vez más asfixiante presencia mediática. Para Marc Angenot (1982, pp.27-37) se puede "hacer aparecer ciertos invariantes, cuyas probabilidades de copresencia en un texto dado son elevados y -con un riesgo mayor de simplificación histórica-asignarles una función en el trabajo ideológico de una sociedad". Sin embargo, "la topología del campo ideológico en el que funciona cada escrito particular" nos ayuda a mensurar la eficacia del discurso, que "habrá de ser variable aun habiendo constancia de los rasgos genéricos." Lo dicho nos pone nuevamente en el andarivel del contexto de la producción y aparición de los discursos, para llamarlos más ampliamente, doxológicos. La acomodación de estos discursos, rodeados por medios de comunicación, se orienta precisamente hacia formas periodísticas o libros de investigación, de reportajes de investigación sociopolítica. De ahí esta afirmación de Oviedo "las fronteras del ensayo se han hecho muy tenues, o simplemente han desaparecido; como resultado se han dado tremendas superposiciones entre ensayos y testimonios, documentales y crónicas" (2006, p. 420). Pocos fueron lo que supieron adaptarse al nuevo escenario. A los tiempos hiper mediáticos se le adosa una muy notable baja en la estimación de la cultura letrada, como consecuencia, las expresiones de la llamada cultura popular filtrada por los mass media se imponen. Prevalece la inmediatez privando al hecho concreto de futuro como de pasado. Mientras que en ensayistas de otras promociones sospechar de la inmediatez como perecedera constituía un modo de enfocar desde los próceres de la historia a los popes de la cultura y exigir la averiguación de las reglas de formación de los conjuntos axiomáticos de la cultura argentina; en los más contemporáneos la realidad se torna presencia absoluta y esencialidad de lo fáctico. La tradición de la sospecha que los ensayistas 
han practicado a fin de desbaratar los lugares comunes parece haber perdido su efectividad. Dice Oviedo:

Mientras que la mayor parte de los mensajes culturales que recibimos hoy son visuales, no se basan en la lectura. ¿Cuáles son las repercusiones de esto en nuestros procesos generadores de imágenes e ideas? La respuesta aún no es nada clara en el mejor de los casos. El ensayo, como respuesta, ha adoptado -y adaptado-nuevas formas para incorporar esta problemática tan cargada y, además, para sobrevivir en una cultura que tiende más y más a la homogeneidad (OVIEDO, 2006, p. 420).

Aquellas miradas en pleno siglo XX, como las del ensayismo de matriz revisionista, hacen alarde de un peculiar recelo hacia la cultura letrada. Pero también aquí es preciso marcar las diferencias. En corrientes ensayísticas anteriores a la que pertenecía un ensayista como Arturo Jauretche, primaba una marcada desconfianza hacia el aparato cultural argentino, en base a una acusación muy precisa: la cultura letrada había apuntalado a una clase social -la oligarquía terrateniente - e impedido que la Argentina rompiera con una situación de sojuzgamiento frente a los poderes imperiales. Mediante lo cual, Arturo Jauretche puso de relieve la importancia de las formas verbales, es decir letradas, para el examen de la experiencia imperialista. Estudios más recientes, como los de Edward Said en Orientalismo (1978) y luego en Cultura e imperialismo (1993) han tratado de destacar los vínculos entre imperialismo y ciencias humanas. Said exploró el modo en que las sociedades colonialistas europeas construyen discursivamente una imagen de las culturas no metropolitanas, en especial de aquéllas que se encuentran bajo su control territorial. En tal sentido, Said fue mucho más allá de Michel Foucault, quien había intentado mostrar las reglas de formación de un discurso y los modos de configuración de la verdad, la manera como circula o es administrada por determinadas instancias de poder. A la luz de estos estudios, podríamos decir que obras como la de Jauretche se registran dentro de las interpretaciones que exploran la inscripción verbal de las experiencias de subordinación, con lo que se confirmarían algunas de sus hipótesis.

Con todo, la desconfianza en la cultura letrada, con sustantivas variantes en algunos casos, no es nueva y puede remontarse más allá del siglo XX. En efecto, y para poner sólo unos ejemplos, Simón Rodríguez 
bregó por la consulta al genio americano para la construcción de nuestras repúblicas y no a la experiencia europea que impregnaba la cultura letrada. "O inventamos o erramos" decía el maestro de Simón Bolívar. Más tarde, José Martí opuso a los "letrados artificiales" el "hombre natural”, que representaba la originalidad americana, más genuina y productiva que las interpretaciones venidas del Occidente culto. Jauretche expresaba este fenómeno a su manera para dar cuenta de la "experiencia del presente", que nos preocupa:

En el lenguaje llano de todos los días, hilvanando recuerdos, episodios o anécdotas, diré mis cosas como se dicen en el hogar, en el café o en el trabajo. Sería muy feliz si el lector adquiere en esta modesta lectura, el hábito de someter las suyas a la crítica de su modo de pensar habitual, utilizando la comparación, la imagen, la analogía y las asociaciones de ideas con que se maneja en su mundo cotidiano. Le bastará esto para salir de la trampa que le tienden los expertos de la cultura (JAURETCHE, 1973, p. 20).

La trampa, a nuestro entender, no ha sido otra que la proveniente de los múltiples comportamientos disociativos registrados entre la ciudad real y la ciudad letrada, como lo vio Ángel Rama (2004) en su célebre estudio. Es decir, un sistema simbólico que solo responde vagamente a los datos particulares y concretos que pudieron darle nacimiento y se han desarrollado independientemente como significaciones desprendidas de sus significantes. Una vez constituido el sistema de significación letrada se impone sobre lo real como una red que lo envuelve. La sacralización de la escritura es un proceso largo y sinuoso, que parte desde la Colonia, especula Rama, creando una legión de burócratas encargados de guardar celosamente la interpretación de la letra, merced a lo cual se situaban en el pináculo de la consideración social. El resultado fue la consolidación de una diglosia, es decir, la nítida separación de dos lenguas: la pública y aparato del poder político y la popular y cotidiana. Por el camino de la lengua popular, rescatada del círculo simbólico de las significaciones de la cultura letrada, ciertos ensayistas pertenecen, sin dudas, al corpus de obras de circunstancias, pero la inmediatez es lo que, precisamente, asigna a su obra la perennidad, como la alcanzada en su momento por el Facundo o en otro género el Martín Fierro. La vinculación con estas obras es a nivel del tema y la forma circunstanciada, en modo alguno, por razones 
estéticas. Jauretche compensaba, como él mismo decía, su "debilidad literaria frente a plumas consagradas" con "la validez de los argumentos", por eso cultivó el género ensayístico, que más que un género fue un método para la dilucidación de este enigma argentino: ser una nación con un potencial para grandes realizaciones y languidecer constantemente en la impotencia.

Salvando todas las distancias, Beatriz Sarlo observa que el declive del discurso ensayístico se produce a partir de una profesionalización de la crítica o como ella misma sostiene por el ingreso del estructuralismo a las academias. El discurso objetivado, la exclusión de la primera persona y la asepsia de la estructura fueron los recursos ideales para la denostación del ensayo entendido solamente como un discurso doxológico y por tanto pasajero, irrelevante. El "daño" ya estaba hecho: con el destierro del ensayo de las academias se extraviaron los caminos de un pensamiento crítico y original a contramano de la asertividad y confianza del escrito académico. Se había ganado en método y perdido en imaginación, parece decirnos Sarlo (1984, pp. 6-11; 1988, pp. 22-23; 2001, pp. 16-310).

\section{La violencia política. Usos de la memoria.}

Otro momento significativo con el que se puede contrastar el ensayo de entresiglo es el de los años 60 y 70 del siglo $\mathrm{XX}$, que estuvo signado en gran medida por los acontecimientos políticos de Cuba. Contemporáneamente, por el aislamiento al que fue sometida la revolución triunfante en 1959 por gran parte de los países latinoamericanos, arrojó a la revolución cubana a los otrora poderosa Unión Soviética. También por la respuesta del castrismo a ese aislamiento, haciendo de la guerrilla una "marca registrada" lista para exportar y generar revoluciones similares en países que practicaban la indiferencia hacia la isla. Para más datos de la estrecha relación de Cuba con el resto de América Latina, para bien o para mal, la historia política de los 60 y 70 del siglo pasado sería inexplicable sin la omnipresencia de la figura de Fidel Castro y el conjunto de mitos revolucionarios que se crearon en torno a la victoria de los rebeldes de Sierra Maestra. La hazaña rodeó de un enorme prestigio la acción política directa que, al margen de nacionalidades, corrió como un reguero de pólvora (nunca mejor usado este lugar común) por muchos países latinoamericanos. La revisión del pasado político reciente de la Argentina y otros países latinoamericanos, como Venezuela, Colombia, Perú, Bolivia, es decir, donde hubo guerrilla no puede hacerse desde luego al margen de la historia de la revolución 
Formas de leer el ensayo argentino en el tránsito de un siglo a otro (XX al XXI) | 19

cubana. En el caso de la Argentina, por añadidura, porque uno de sus líderes más carismáticos y controvertidos era oriundo de ese país: el "Che" Guevara.

¿Qué parte de la historia de la revolución cubana nos toca más de cerca? Sin dudas, la admiración que despertó en la juventud y la esperanza que renació en las luchas nacionales al quedar demostrado que los regímenes oprobiosos (como el de Fulgencio Batista) podían derrotarse. Pero también algunas simplificaciones del debate y la historia política de América Latina que deben revisarse, cuando se juzgue críticamente la militarización de la actividad política a partir de 1959. Lucha política o lucha armada, así pasó a definirse, en general, el debate ideológico después del triunfo castrista, con el consecuente desprestigio por la actividad que no estuviera asociada a la acción armada. La jerga militar sustituye a la dialéctica, la organización vertical a la persuasión, en tanto que desaparece la posibilidad de generar consensos en torno a polos programáticos por ser consideradas prácticas burguesas, acuerdistas, regiminosas y un largo etcétera de epítetos desacreditadores. Es así como se trata de imponer la teoría del foquismo: voluntarismo, indiferencia a la lucha de masas, desconfianza hacia la "ciudad", idealización del campesino, liquidación del partido político. Si traemos a colación este periodo lo es porque con la implosión del sistema político del año 2001 en la Argentina, las así llamadas miradas "setentistas" retornarían por sus fueros de la mano del poder político. Habrá de ser nuevamente Beatriz Sarlo quien vea con ojos críticos estos fenómenos en el sentido de que la proliferación del testimonio clausuró en gran medida la reflexión sobre los “años de plomo". Nos recuerda Sarlo:

Susan Sontag escribió: "Quizá se le asigna demasiado valor a la memoria y un valor insuficiente al pensamiento". La frase pide precaución frente a una historia en la que el exceso de memoria (cita a los serbios, a los irlandeses) puede conducir, nuevamente, a la guerra. Este libro no explora en la dirección de esas memorias nacionales guerreras, sino en otra, la de la intangibilidad de ciertos discursos sobre el pasado. Está movido por la convicción de Sontag: es más importante entender que recordar, aunque para entender sea preciso, también, recordar (2005, p. 25).

En efecto, el uso del yo es legítimo siempre y cuando no procure convertirse en la única fuente de veracidad de los hechos. Durante este 
período en el que la pregunta era cómo narrar la historia reciente (Sarlo), la primera persona del ensayo dejó paso al yo testimonial, perdiéndose de esa manera la actitud crítica, reflexiva e inquisidora que un género le resta a otro (OYOLA, 2006, pp 149-153). En este contexto puede recordarse a José Pablo Feinmann, La sangre derramada. Ensayo sobre la violencia politica (1999) que consiste en un análisis de la violencia en la historia argentina. Un libro que recorre ese flagelo de derecha a izquierda. O uno más reciente como de Marcelo De Larraquy, Argentina. Un siglo de violencia (2017).

\section{El kirchnerismo. Campo, identidad nacional y crisis.}

Durante el año 2003 se produjo la que se denominó la crisis del campo, en relación con una resolución ministerial 125 , que proponía un cambio en los gravámenes a las extraordinarias ganancias que la producción agropecuaria estaba produciendo. El antiguo conflicto de la renta agraria volvió a plantearse. ${ }^{4}$ Este episodio constituyó un cambio de rumbo de enormes consecuencias, positivas y negativas. ${ }^{5}$ Ayudó además a crear, desde sectores opositores al kirchnerismo gobernante nociones como "relato", "la grieta", "políticas setentistas" y otras tantas. Con posterioridad a estos acontecimientos Ricardo Forster escribió un ensayo titulado La anomalía kirchnerista (2013). La alusión anómala en la política resultaba una síntesis interesante de lo que ocurría y había venido ocurriendo en la Argentina hasta entonces, en lo que respecta a aquella restauración liberal a la que aludimos.

El conflicto del campo se visualiza como un parte aguas en la política y entre los intelectuales. El grupo "Carta abierta" ${ }^{6}$ habrá de ser

${ }^{4}$ El precio de la tonelada de soja rondaba los 460 dólares, en consecuencia de acuerdo con este precio internacional la aplicación del sistema de retenciones móviles sería del 39\%, nada más que 4 puntos por encima de cuando comenzó el conflicto, que estaba en el orden del $35 \%$. Baste este dato entonces como un indicador de que la pulseada tenía componentes menos visibles, de raíz políticoideológica, lo que en rigor de verdad es lo menos que se ha atendido.

${ }^{5}$ Existe una interesante y amplísima bibliografía en gran parte ensayística que ha sido recogida por el historiador Darío Pulfer. Pulfer, Darío. Materiales bibliográficos para el estudio del kirchnerismo. Disponible en <http://www.peronlibros.com.ar/content/pulfer-dario-materiales-para-el-estudiodel-kirchnerismo>.

${ }^{6}$ Así se dio en llamar un grupo de intelectuales que salieron en apoyo de las políticas del gobierno de Néstor y Cristina Kirchner. 
Formas de leer el ensayo argentino en el tránsito de un siglo a otro (XX al XXI) | 21

una de las consecuencias inmediatas, como también la aparición de otras vertientes teóricas sobre el campo popular. El teórico Ernesto Laclau manifestó su adhesión al rumbo de la política kirchnerista y reivindicó dos conceptos fundamentales: por un lado el populismo y por otro la política como polemos, es decir un enfrentamiento entre amigo-enemigo. Estas variantes que ingresaron al pensamiento político tuvieron en el conflicto del campo su, diríamos, laboratorio. "Todos somos el campo" fue la consigna de los dirigentes ruralistas, en un intento de dar a sus reclamos un carácter de epopeya nacional. Esta idea de pertenencia resultaba extremadamente sospechosa, habida cuenta de que la mayoría de los argentinos no eran beneficiaros de los enormes negocios que se realizaban sobre la base de la explotación agropecuaria. Si bien puede ser cierto que la ley de herencias había hecho más por la liquidación del latifundismo que cualquier medida política al respecto, no es menos cierto que, aunque las extensiones explotadas fueran menores, nada indica que los paradigmas culturales con los que los recientes y más numerosos propietarios de las tierras más feraces hubieran variado. Asomaba un costado cultural del conflicto, a través de las dimensiones simbólicas y figuraciones ideológicas con la que se desencadenaba el enfrentamiento. $\mathrm{O}$ mejor, sin ellas no había posibilidad de comprender más cabalmente lo que estaba en juego, es decir, una noción de país.

Ante todo, una precisión sobre las denominaciones emergentes. Cuando se dice el "campo" no se está aludiendo a un factor geográfico, sino a una construcción del tipo "geocultural" en el sentido de que absorbe elementos referidos al espacio, pero dentro de una designación cultural deliberadamente amplia hasta convertirla en inofensiva. La denominación envolvente tiene una motivación inocultable, esto es, producir una asociación inmediata entre el vocablo "campo" y un conjunto de valores que se asocian a una cultura del trabajo y un decálogo de virtudes basadas en ella. Laboriosidad, sacrificio, honestidad, bonhomía, entrega desinteresada son algunas aristas valóricas que surgen "espontáneamente". Esta formación discursiva, no obstante, no posee un origen natural o espontáneo, debe buscarse en nuestros mitos de la identidad nacional y las narrativas de la nacionalidad. De manera que al debate económico es necesario agregarle un debate simbólico, a fin de desbrozar los elementos que están en danza y determinar los límites de las soluciones.

La identidad nacional que se forja en el momento de mayor esplendor agropecuario argentino, hacia el primer centenario, coincide con la desaparición de la figura gauchesca como personaje representativo 
de las pampas. Su declinación inaugura el ciclo de la apropiación cultural, con el fin de reciclar la figura del gaucho y extraerle así tanto los componentes conflictivos como los condenables vínculos con las montoneras del siglo XIX. No es sino un afán civilizatorio lo que mueve estratégicamente a la cultura letrada a la hora de tomar para sí el mito gaucho. Desde Leopoldo Lugones hasta Martínez Estrada, la literatura argentina creó una tradición gauchesca a partir del Martín Fierro, el famoso poema de Hernández. Despojado de esa manera, el gaucho consigue su ingreso a la galería de la representatividad nacional, como elemento de identidad y fundador de una nacionalidad. No hay espacio para referirnos a estos fenómenos de "invención de una tradición", que nacen por iniciativa de un cúmulo de intereses sectoriales para transformarse luego en una visión conjunta, ampliamente aceptada. Esta tradición inventada volvió a activarse durante los episodios referidos al conflicto con el campo.

\section{De la academia al ágora}

Sarlo puede ser nombrada solamente por su apellido, en virtud de que se ha convertido prácticamente en una marca. A su nombre se ha soldado un posicionamiento, un rótulo de intelectual que se vale de su saber académico para hablar llanamente a un público más amplio. Algunos de los textos que podríamos indicar de Beatriz Sarlo son los siguientes: Siete ensayos sobre Walter Benjamin (2011). Si bien no se le debe a ella la introducción de la obra benjaminiana en la Argentina, ha sido una de las lectoras más finas que ha tenido el pensador alemán. Sarlo y los grupos a los que ha pertenecido, como el caso de la revista Punto de Vista, supieron animar el debate intelectual apelando a otras fuentes por entonces desconocidas para la mayoría de los círculos intelectuales. Entre esos méritos debe destacarse la introducción de la obra de Raymond Williams como un modo de contrarrestar otras teorías de procedencia parisina. Sarlo pone en evidencia en este texto que la obra de Benjamin ha sido como una caja de herramientas para su propio trabajo de reflexión. Desde aspectos biográficos a los temas elegidos por Benjamin, la ensayista argentina hace un recorrido de la vida a la obra y de ésta nuevamente a la vida. En La maquina cultural (2007), Sarlo pareciera animarse a la 'narratio', una instancia retórica que es propia del ensayo, al contar tres historias que atraviesan el siglo XX que van de la pobreza y la marginalidad al lujo y el privilegio representado en la figura de Victoria 
Formas de leer el ensayo argentino en el tránsito de un siglo a otro (XX al XXI) | 23

Ocampo y una tercera que alude a la celeridad de los años 70 del siglo XX. La pasión y la excepción (2003) en esta obra convergen episodios de la historia argentina y el personaje-mito: Eva Perón, el Gral. Aramburu y Jorge Luis Borges. Verdaderamente, Sarlo logra apresar en estos personajes conjuntos histórico-culturales, en los que el encono, el desprecio o el hostigamiento fueron la amalgana. Nada más lejos uno de otro personaje, sin embargo los termina reuniendo la pasión y la excepcionalidad en la que actuaron. Escenas de la vida posmoderna (2014) nos sitúa frente a una dominante cultural de la década de los noventa y la llamada posmodernidad: comida rápida, videos juegos, el zapping como operación desconocida hasta entonces. Sarlo nos enfrenta a los dilemas de los avances tecnológicos y los medios masivos de comunicación y el cambio de paradigmas culturales y artísticos. Viajes (2014) oscila entre el ensayo y la biografía: es un recorrido por América Latina desde la memoria y el auxilio de la fotografía. También supone un viaje iniciático que todo joven de entonces estaba obligado a realizar para "entender" la realidad latinoamericana.

\section{Desmontando mitos}

Otra variante que se impuso tanto desde el ensayo histórico como el sociológico fue la operación de desmontaje de algunos mitos argentinos. Es el caso de Felipe Pigna, Los Mitos de la Historia Argentina, 2, (2005). En la clásica línea de la 'historia maestra de vida', Pigna incursiona en el pasado para poder pensar el presente, a través de figuras controvertidas de la historia argentina: desde San Martín, pasando por Rosas y Sarmiento. El camino que traza Pigna procura desandar los recorridos de la identidad argentina. El otro caso es el de Alejandro Grimson, Mitomanias argentinas (2012). El sociológico es más metódico ya que toma un mito y lo analiza hasta desarticularlo. Echa mano a una ácida crítica a los lugares comunes del discurso público, que sin evidencia alguna crea un tópico al que se aferra luego como si se trataran de una verdad incontrastable: nuestra procedencia europea dando la espalda a América Latina, que la inmigración de países limítrofes es la responsable de la desocupación o que Chile va por el camino correcto en economía y republicanismo, etc. Grimson nos convence de que tener una mirada más compleja y cabal de nosotros mismos es un primer paso para construir una sociedad mejor. 
En este apartado podríamos incluir dos textos ensayísticos más: Argentinismos (2011) de Martín Caparrós y Argentinos de Jorge Lanata (Edición Definitiva, 2008). No sólo por la coincidencia de sus títulos, sino porque también el tono que los caracteriza son similares. Si Lanata mira el pasado lo es con el propósito de dilucidar la procedencia de ese carácter argentino que se revela en la constatación de que el argentino tiene la memoria inmediata obstruida, porque es capaz de incurrir en los mismos errores pese a que ya fueron cometidos. Caparrós también habla de la realidad actual pero apelando a términos que luego desmenuza parsimoniosamente.

\section{Miradas a la economía}

Eduardo Luis Curia en El modelo de desarrollo en la Argentina (2011) es uno de los pocos que plantea en su texto la dualidad representada por los dos grandes modelos que han prefigurado la Argentina, aquel que pone las prioridades en el desarrollo del mercado interno e impulso a un desarrollo integral y en el otro extremo el modelo provisto por el liberalismo en sus diversas formas políticas. Más proclive a dar continuidad a la orientación neodesarrollista que impulsó el gobierno de Néstor Kirchner que de una vuelta al neoliberalismo, Curia es consciente de que los cambios mundiales son cruciales para desequilibrar la balanza. Por su lado, Flavio Gaitán El rescate del estado (2013) reflexiona sobre la necesidad de sostener el fenómeno que fue iniciado apenas se abrió el siglo XXI en varios países de América Latina, que consistió en la adopción de una dirección opuesta al proyecto neoliberal. Eric Calcagno y Alfredo Eric Calcagno en El rumbo argentino (2013) llevan a cabo una defensa de lo realizado en materia económica desde el año 2003, instando a que el proceso se profundice.

A modo de conclusión, se puede decir que no resulta fácil a la luz de la propuesta metodológica que hemos realizado establecer un vínculo conector entre aquella restauración liberal que impregna todo el periodo de entresiglo y la producción ensayística, no obstante este primer corolario se obtiene mediante la lectura densa que se propuso. Exceptuando los ensayos de orden económico, el resto no se preocupa por abordar desde el género ensayístico, por ende, asumiendo una actitud crítica frente al fenómeno de la restauración liberal, a no ser que nos 
refiramos a la ensayística de izquierda ${ }^{7}$. Más aún, es un tema sorprendentemente ausente. Aun así el ensayo político-cultural es tal vez el que más ha sobresalido. El espacio del ensayo político-cultural, además de los ensayistas aludidos, estuvo ocupado en el tránsito de siglo a otro por Beatriz Sarlo -como vimos-, a los que habría que sumar a Juan José Sebrelli y Josefina Ludmer. De los tres, el centro lo ocupa Sarlo porque su producción ensayística ha sido muy prolífica y de amplia difusión. Además de que a su prestigio académico le añadió la veta de animadora del debate político durante los tiempos del kirchnerismo, especialmente por su marcada oposición que le abrió las puertas de las grandes corporaciones mediáticas, como la del Grupo Clarín. Pero existe un antecedente más que es digno de destacar, desde 1978 con la creación de la revista Punto de Vista (inicialmente dirigida por Jorge Sevilla e integrada por ella, Carlos Altamirano y Ricardo Piglia) en adelante no ha dejado de participar en la vida cultural argentina, inmersa siempre en debates polémicos. Sarlo representa el tránsito de lo literario-académico a la política, es decir, leer la política con pautas dadas por la literatura. La otra ensayista, Josefina Ludmer, implica un caso de transición de la política a la literatura, entendiendo por ello, que la literatura es política. Mientras que Sebrelli se ubica en una perspectiva denostadora de lo político.

Un aproximado balance del escenario de un siglo a otro dejaría como saldo que hubo renovación temática, ya que se abandonaron algunas preguntas muy intensas formuladas durante el siglo XX y se confeccionaron otras. Desde ese punto de vista, se dejó de lado la interrogación sobre el qué somos y se la reemplazó por el cómo somos. También ha habido cambios estructurales, en tanto que la blogóesfera amplió el campo de irradiación del ensayo (V.TEDESCHI, 2012, pp. 657 679). Si el ensayo escrito, tal como lo conocemos, es el simulacro de un diálogo, la ensayística en la red facilita que el diálogo se produzca a través de los comentarios del lector 'on line'.

\footnotetext{
${ }^{7}$ Habría que continuar la cartografía de esta ensayística de izquierda, tomando como punto de partida el trabajo de Bonano, Mariana (2005). "Ensayo polémico y la crítica literaria de izquierda en Argentina. Apuntes para un debate sobre poéticas realistas y narrativa nacional en la década del 60" en Anclajes IX. 9 (diciembre): 17-37.
} 


\section{BIBLIOGRAFÍA}

ANGENOT, Marc. La parole pamphlétarie. Contribution a la tipologie des discuours modernes. Selección y traducción a cargo de Roberto Bein. París: Payot, 1982.

BONANO, Mariana. Ensayo polémico y la crítica literaria de izquierda en Argentina. Apuntes para un debate sobre poéticas realistas y narrativa nacional en la década del 60. In: Anclajes IX. 9 (diciembre), 2005.

CHARTIER, Roger. El mundo como representación. Estudios sobre historial cultural. Trad. Claudia Ferrari. Barcelona: Gedisa, 1992.

DE GRANDIS, Rita. Introducción: El ensayo entre la ficción y el pensamiento. In: Revista Iberoamericana, Vol. LXXVIII, Núm. 240, Julio-Septiembre, 2012.

EICHENBAUM, Boris. El ambiente social de la literatura. In: Antología del formulismo ruso y el Grupo de Bajtin. Intr. y ed. Emil Volek. Madrid: Editorial Fundamento, 1992.

GOIC, Cedomil. Historia de la novela hispanoamericana. Santiago de Chile: Ediciones Universitarias de Valparaíso, 1972.

GUTIERREZ GIRARDOT, Rafael. Modernismo. Supuestos históricos y culturales. 1º ed. 1987. Bogotá: Fondo de Cultura Económica, 2004.

JAMESON, Fredric. Marxismo y posmodernismo. In: El giro cultural. Escritos seleccionados sobre el posmodernismo, Buenos Aires: Manantial, 2002.

JAURETCHE, Arturo. Los profetas del odio y la yapa. Buenos Aires: Peña Lillo, Editor S. R. L., 1973.

LUDMER, Josefina. Temporalidades del presente. In: Boletin del Centro de Estudios de teoría y crítica literaria, n. 10, 2002.

OYOLA, Gonzalo. Más importante que recordar es entender. Sobre Tiempo pasado de Beatriz Sarlo, Katatay, n 3/4, may., 2006.

OVIEDO, José Miguel. El ensayo moderno en Hispanoamérica. In: Historia de la literatura hispanoamericana. T. II. Madrid: Gredos, 2006.

PULFER, Darío. Materiales bibliográficos para el estudio del kirchnerismo. Disponible en $\langle$ http://www.peronlibros.com.ar/content/pulfer-dariomateriales-para-el-estudio-del-kirchnerismo>.

RAMA, Ángel. La ciudad letrada. Pról. de Carlos Monsiváis. Santiago de Chile: Tajamar Editores, 2004.

SARLO, Beatriz. La crítica: entre la literatura y el público. In: Espacios de crítica y producción, no 1, 1984. 
Formas de leer el ensayo argentino en el tránsito de un siglo a otro (XX al XXI) | 27

Respuesta a la Encuesta a la crítica literaria. In: Espacios de crítica y producción, no 7, 1988.

. Del otro lado del horizonte. In: Boletin/9, 2001.

. Tiempo pasado. Cultura de la memoria y giro subjetivo. Una discusión. Buenos Aires: Siglo XXI Editores Argentina, 2005.

TYNIANOV, Iuri. Sobre la evolución literaria. In: Antología del formulismo ruso y el Grupo de Bajtin. Intr. y ed. Emil Volek. Madrid: Editorial Fundamento, 1992.

V. TEDESCHI, Stefano (2012). El blog: ¿una nueva frontera para el ensayo? In: Revista Iberoamericana, Vol. LXXVIII, Núm. 240, JulioSeptiembre, 2012.

WEINBERG, Liliana. El ensayo en diálogo, De la tierra firme al archipiélago relacional. In: Transnacionalidad e hibridez en el ensayo hispánico. Un género sin orillas, editado por Reindert Dhondt y Dagmar Vandebosch. Leiden; Boston: Brill, 2017.

Recebido em: 08/04/2018

Aceito em: 17/04/2018 